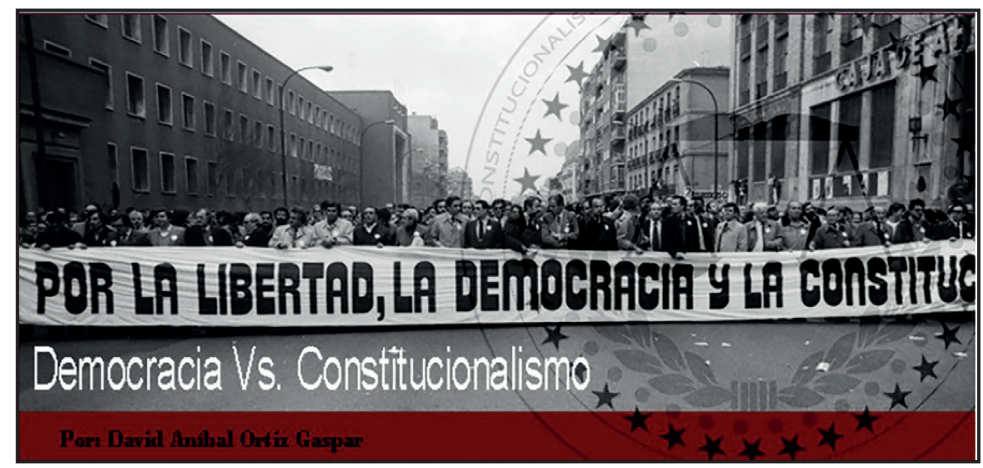

http://www.constitucionalista.net/democracia-vs-constitucionalismo/

\title{
DEMOCRACIA Y CONSTITUCIONALISMO: EL CARÁCTER CONTRAMAYORITARIO DE LA REVISIÓN JUDICIAL López Hidalgo, Sebastián ${ }^{1}$
} Correspondencia: pslopez@uazuay.edu.ec Profesor de Derecho Constitucional, Universidad del Azuay. 


\section{Resumen}

Este ensayo constituye un ejercicio para evidenciar la tensión existente entre dos ideas fuerza: constitucionalismo y democracia. Más allá de la "evidente" complementariedad de los términos, existe una profunda tensión que atraviesa la utilización de estos conceptos. En ese marco, el carácter contramayoritario de la revisión judicial constituye un elemento que, aunque desde una óptica más optimista, relaja dicho conflicto, muestra otras posiciones que denuncian la constante paradoja que refleja para el constitucionalismo un órgano elite de revisión judicial dentro de una democracia. Poner en evidencia esa paradoja constituye el punto central de este artículo.

Palabras clave: constitucionalismo, democracia, dificultad contramayoritaria, revisión judicial.

\section{Abstract}

The present paper tends to be a proposal for a debate between two main ideas: constitutionalism versus democracy. Beyond the evident correlation between them, there is a deep and marked tension among both of them. It is within this frame, that the counter majoritarian character from the judicial review constitutes an element which, from a friendlier perspective, relaxes the tension; there are other positions that declare this constant paradox that reflects for constitutionalism an elite power of judicial review inside democracy. The main core of this article is to put into evidence this paradox.

Keywords: constitucionalism, democracy, judicial review. 


\section{Introducción}

Parecería ser que luego del arduo debate sostenido por Kelsen y Schmitt en tiempos de Weimar a cerca de la legitimidad de la justicia constitucional, ${ }^{2}$ la historia habría dirimido el conflicto en favor de la vigencia de dicha institución, al punto que la jurisdicción constitucional ha tenido una importante expansión durante el siglo pasado. ${ }^{3}$

2 Al respecto puede verse la obra de Carl Schmitt, La Defensa de la Constitución, Madrid, Tecnos, 1983; y, la obra de Hans Kelsen, ¿Quién debe ser el defensor de la Constitución?, Madrid, Tecnos, 1995.

3 Aun cuando sea un punto discutible hoy en día, dado el carácter jurisdiccional que ha adquirido el órgano de revisión constitucional en Francia, según la investigación de Albert Noguera, ¿Democratizando la justicia constitucional? La articulación entre soberanía, justicia constitucional y participación en el viejo y el nuevo constitucionalismo, en Oñati Socio-Legal Series, v. 1, n. 2 (2011) - Investigaciones Ikerlanak http://papers.ssrn.com/sol3/papers.cfm?abstract id=197532. (Acceso 28 de agosto de 2014). "Seguramente a excepción del caso de Francia, donde fruto de la herencia adquirida con la revolución francesa, el órgano que ejerce control de constitucionalidad (el Conseil Constitutionnel) no es un órgano jurisdiccional sino político, en el resto de países del mundo, existe, en la actualidad, un modelo judicializado de revisión constitucional...". Por su parte, Pierre Bon ha manifestado en relación al caso francés que, "...el control parecía servir, esencialmente, para marginar al legislador en su ámbito y forzarle a respetar las reglas obligatorias del procedimiento legislativo. Con la decisión de 1971, y la abundante jurisprudencia que la sigue, la protección de los derechos fundamentales aparece en primer plano de las funciones de control de la constitucionalidad de las leyes, como hace tiempo sucedía en otros países dotados de una jurisdicción constitucional. Así, se pasa, en cierto modo, de 
Aun así, la polémica sobre la legitimidad de la justicia constitucional, con diferente intensidad, resurge de tiempo en tiempo en razón del papel activista -judicial activism-, o de una autolimitación judicial -judicial self-restraintasumido por las Cortes o Tribunales. ${ }^{4}$

A este problema, el de la legitimidad de la revisión judicial, es el que se ha referido Alexander Bickel con indudable éxito, al haber acuñado la expresión "dificultad contramayoritaria" para plantear el cómo justificar desde una teoría democrática la vigencia de órganos de revisión judicial no democráticos, encargados de controlar la constitucionalidad de normas provenientes del depositario de la soberanía popular, esto es, el parlamento. ${ }^{5}$

un control de la constitucionalidad ejercido sólo en interés de los poderes públicos, y en particular del Ejecutivo, a un control de constitucionalidad ejercido también en interés de los ciudadanos...". Véase, Pierre Bon, "Francia" en Eliseo Aja (edit.), "Las tensiones entre el Tribunal Constitucional y el legislador en la Europa actual", Barcelona, Ariel, 1998, pp. 138-139. También, en la investigación de Javier Pardo Falcón, El Consejo Constitucional Francés. Madrid, Centro de Estudios Constitucionales, 1990, pp. 111-113, ha quedado claro que, aunque en un inicio la función del control de constitucionalidad quedaba concebida de una forma absolutamente marginal en los inicios de la Quinta República, en la actualidad, una vez superadas ciertas limitaciones que hacían presumir que muy pocas veces sería activado el control de constitucionalidad, éste se manifiesta en su verdadera dimensión de protección de los derechos fundamentales y libertades públicas. Algo que era inimaginable en un primer momento.

4 Eduardo García de Enterría, La Constitución como norma y el Tribunal Constitucional, 4ta. ed., Madrid, Civitas, p. 167.

5 Alexander Bickel ha utilizado esta expresión para negar la validez de los argumentos que intentan justificar la revisión 50 


\section{Dificultad contramayoritariayjusticia constitucional}

Con independencia del modelo de justicia constitucional adoptado, si la ley está objetivada por la Constitución y la Constitución por su intérprete, ya que no existe ninguna norma superior dentro del ordenamiento jurídico positivo, ${ }^{6}$ surgen interrogantes acerca de si existen o no parámetros objetivos del control cuando quien realiza la interpretación es una Corte o Tribunal y lo que se trata de interpretar es nada menos que la Constitución. ¿Quién debe tener la "última palabra" cuando lo que se interpreta es la Constitución en una democracia? ¿Qué es lo que justifica que un grupo de personas no elegidas por el pueblo puedan ejercer una revisión judicial de la ley como la más alta expresión de la voluntad popular? ¿Cómo las Constituciones pueden inspirar lealtad a pesar de los constantes desacuerdos que se suscitan en relación con sus contenidos, muchas de las veces plurales y abstractos?

Cuando se conservaba intacto el mito de que el juez se limitaba a aplicar la ley o la Constitución sin tener que valorarla, la falta de legitimidad democrática de los órganos de justicia parecía irrelevante, puesto que la

judicial por antidemocrática. Véase, Alexander Bickel, The Least Dangerous Branch: The Supreme Court at the Bar of Politics, 2da. ed., Yale University Press, 1986.

6 Dejando a salvo la célebre norma fundamental o básica de origen kelseniano, que no se trata propiamente de una norma positiva dictada por algún legislador humano, sino de un presupuesto epistemológico, una especie de hipótesis de trabajo que utilizan implícitamente los juristas en sus elaboraciones con la finalidad de explicar la relación dinámica de derivación y validez de las normas inferiores. 
actividad judicial se concebía como meramente intelectiva y no valorativa. ${ }^{7}$

Precisamente, el problema de la dificultad u objeción contramayoritaria $^{8}$ parece cobrar mayor envergadura

7 Carlos Santiago Nino, Fundamentos de derecho constitucional, Buenos Aires, Editorial Astrea, 1992, p. 683.

8 La crítica contramayoritaria sostendría que, así como el establecer una carta de derechos atrincherada constituiría una limitación injustificada al legislador electo democráticamente, el permitir que los jueces tengan la última palabra acerca del contenido y alcance de una ley implicaría privar a los ciudadanos del derecho a reflexionar libremente mediante sus representantes a través del contenido y alcance de dichas normas. Es extensa la literatura que ha abordado el tema sobre la revisión judicial -defensores y críticos-; sin embargo, es fundamental la referencia a algunos autores. En el ámbito anglosajón marcaron un punto importante Alexander Bickel, The Least Dangerous Branch: The Supreme Court at the Bar of Politics, 2da. ed., Yale University Press, 1986; Jeremy Waldron, Derecho y Desacuerdos, (Law and Disagreement) Madrid, Marcial Pons, Ediciones Jurídicas y Sociales S.A., 2005; John Hart Ely, Democracia y Desconfianza Una teoría del control constitucional (Democracy and Distrust), Colombia, Universidad de los Andes, Siglo del Hombre Editores, 1997; Ronald Dworkin, Freedom's Law. The moral Reading of the American Constitution, Cambridge: Harvard University Press, 1996; Bruce Ackerman, We the People. Foundations, Cambridge, Massachussets: Harvard University Press, 1991; Mark Tushnet, ¿Por qué la Constitución importa? Serie de Teoría Jurídica y Filosofía del derecho. Nro. 63, Colombia, Universidad Externado, 2012; Larry Kramer, The People Themselves. Popular Constitucionalism and Judical Review, Oxford University Press, New York, 2004, por citar algunos de los más destacados, entre otros. Aun cuando las referencias son inabarcables, para el ámbito hispanoamericano es indispensable la consulta a obras importantes y destacadas 
cuando se advierte que muchas de las cláusulas artículos como, Eduardo García de Enterría, La Constitución como norma y el Tribunal Constitucional, 4ta. ed., Madrid, Civitas, 2006; Víctor Ferreres Comella, Justicia Constitucional y democracia, Madrid, CEPC, 1997; Carlos Nino, La Constitución de la democracia deliberativa, Barcelona, Gedisa, 1997; Roberto Gargarella, La justicia frente al gobierno. Sobre el carácter contramayoritario del poder judicial, Ariel, 1996; Juan Carlos Bayón, "Democracia y derechos: problemas de fundamentación del constitucionalismo", en Miguel Carbonell y Leonardo García Jaramillo, Neoconstitucionalismos, Madrid, Trotta, 2010; Víctor Ferreres, "El control judicial de la constitucionalidad de la ley. El problema de su legitimidad democrática" en Miguel Carbonell y Leonardo García Jaramillo, Neoconstitucionalismos, Madrid, Trotta, 2010; José Juan Moreso, "Derechos y justicia procesal imperfecta" en F. Laporta (ed.), Constitución: Problemas filosóficos, Madrid, CEPC, 2003; Juan Carlos Bayón, "Derechos, democracia y Constitución" en F. Laporta (ed.), Constitución: Problemas filosóficos, Madrid, CEPC, 2003; Pablo de Lora, "Justicia constitucional y deferencia al legislador" en F. Laporta (ed.), Constitución: Problemas filosóficos, Madrid, CEPC, 2003; Víctor Ferreres Comella, "Una defensa de la rigidez constitucional" en F. Laporta (ed.), Constitución: Problemas filosóficos, Madrid, CEPC, 2003; Claudia Orunesu, Positivismo jurídico y sistemas constitucionales, Madrid, Marcial Pons, 2012; Sebastián Linares, La (i)legitimidad del control judicial de las leyes, Madrid, Marcial Pons, 2008; Roberto Gargarella, "Las amenazas del constitucionalismo: constitucionalismo, derechos y democracia", Los derechos fundamentales, Marcelo Alegre, ed. al., Buenos Aires, Editores del Puerto, 2003; Roberto Gargarella, "Constitucionalismo versus Democracia" en Teoría y crítica del derecho constitucional, Abeledo Perrot, 2008; Francisco Laporta, "Norma básica, constitución y decisión por mayorías" en F. Laporta (ed.), Constitución: Problemas filosóficos, Madrid, CEPC, 2003, entre otros, así como innumerables artículos y demás publicaciones. 
constitucionales están generalmente expresadas en términos altamente vagos y abstractos, con un fuerte contenido valorativo ¿Significa esto rendirse a los argumentos contramayoritarios que llevan, en definitiva, al rechazo del control judicial, acentuando el carácter elitista y antidemocrático de la función de revisión? ${ }^{9}$

La tesis de un gobierno de los jueces ${ }^{10}$ generalizada después en Europa con el libro de Lambert ${ }^{11}$ como un gobierno carente de legitimación democrática e

$9 \quad$ Claudia Orunesu y otros, "Los límites de la interpretación en la democracia constitucional" en Estudios sobre la interpretación dinámica de los sistemas constitucionales, México, Biblioteca de Ética, Filosofía del Derecho y Sociedad, Fontamará S.A, 2005. p. 56.

10 Cesáreo Rodríguez-Aguilera de Prat, "Norberto Bobbio y el Futuro de la Democracia" en Working papers-Documentos de trabajo, Barcelona, Instituto de Ciencias Políticas y Sociales, núm. 125, 1997, p. 9, refiriéndose al trabajo de Norberto Bobbio dice: "Al final, señala Bobbio, la cuestión del gobierno de las leyes versus gobierno de los hombres acaba siendo una pregunta mal formulada, ya que lo uno no excluye a lo otro, puesto que aquellas son elaboradas por éstos...sólo la democracia basada en el principio de legalidad con división equilibrada de poderes permite hacer compatibles los dos elementos aparentemente antitéticos de la pregunta".

11 La obra de Edouard Lambert, El gobierno de los jueces (Le gouvernement des juges) publicada en 1921 es un trabajo que lleva a cabo un análisis crítico de la justicia constitucional en los Estados Unidos. Haciéndose eco de las principales aportaciones de la literatura jurídica estadounidense del momento, Lambert pone de manifiesto los inconvenientes que conlleva la atribución a un órgano judicial de la facultad de revisar la obra del legislador. Véase la obra de Lambert, El gobierno de los jueces y la lucha contra la legislación social en los Estado Unidos, con estudio preliminar de Luis Pomed, Madrid, Tecnos, 2010, trad. Félix de la Fuente. 
irresponsable respecto de sus actuaciones, tiene su origen en contextos como el de los Estados Unidos desde que Theodore Roosevelt, en respuesta a las sentencias del Tribunal Supremo norteamericano condenara el papel del legislador irresponsable asumido por el juez, papel que los jueces americanos se han atribuido unilateralmente. ${ }^{12}$

Constantemente los defensores del principio democrático mayoritario han sostenido que el establecer una carta atrincherada de derechos o confiar la guarda de la supremacía constitucional a órganos elitistas no democráticos (Cortes - Tribunales Constitucionales), permitiéndoles conservar la última palabra en temas constitucionales, constituye una afrenta y una limitación injustificada al legislador democrático, que afecta a las bases mismas de una sociedad democrática.

Por otro lado, hay quienes sostienen con destacados argumentos que "la razón de ser de la justicia constitucional es su función anti-mayoría, ejerciendo la cual limita, por así decirlo, la cantidad de democracia para preservar su calidad, para evitar que se transforme en un régimen ciego, rendido al mero número que puede todo lo que quiere, que cambia derechos...". ${ }^{13}$ Es decir, se acepta que la justicia constitucional no forma parte "natural" de la democracia,

12 B. Schwartz, autor citado por Eduardo García de Enterría, "La Constitución como norma y el Tribunal Constitucional...", p. 178; José Luis Cascajo Castro, "La jurisdicción constitucional de la libertad" en Revista de Estudios Políticos, núm. 199, 1999, p. 174, con el fin de evitar el gobierno de los jueces -gouverment des judges- ha hablado de una praxis feliz y coherente que debe ser desarrollada por los tribunales, alejada de las tentaciones y de los secretos.

13 Gustavo Zagrebelsky, Principios y votos. El Tribunal Constitucional y la política, Madrid, Trotta, 2008, p. 102. 
pero sirve a la democracia de forma sustancial. ${ }^{14}$

Desde Kelsen se insistiría en que no se debía confundir principio de la mayoría (la democracia verdadera), con dominio de una mayoría (el simple mayoritarismo), ${ }^{15}$ de forma que el Estado constitucional resultaría ser, precisamente, la juridificación de la democracia, que excluye la posibilidad de aplicar métodos democráticos orientados a su propia supresión o desconocimiento. ${ }^{16}$

14 José Juan Moreso, "Derechos y justicia procesal imperfecta" en Francisco Laporta, Constitución: problemas filosóficos, Madrid, Centro de Estudios Políticos y Constitucionales, 2003 , p. 397, sostiene que el control judicial de constitucionalidad es un instrumento que puede ser adecuado para proteger los derechos constitucionales, aunque no sea un mecanismo estrictamente necesario para la existencia de una democracia constitucional.

15 Hans Kelsen, Esencia y valor de la democracia, 2da. ed., Madrid, Guadarrama, 1977, pp. 81-85. trad. Rafael Luengo Tapia y Luis Legaz y Lacambra. Ahora bien, Anna Pintore "Democracia sin derechos. En torno al Kelsen democrático", en Doxa. Cuadernos de Filosofía del Derecho, núm. 23, 2000, pp. 135-136, expone que Kelsen, a pesar de que no ignora la tensión entre derecho y democracia, soberanía popular y constitución, nunca elaboró una teoría de la democracia constitucional en el sentido de una concepción que afrontase expresa y sistemáticamente el problema de conciliar los dos polos, sino sólo, por separado, una teoría de la democracia y una teoría de la Constitución. Más aún, uno de los problemas más críticos de las democracia constitucional relativo a la objeción contramayoritaria, vendría a ser tratado por Kelsen de forma muy concisa y seguramente insatisfactoria, rechazando que las Constituciones apelen a términos abstractos o generales o que se remitan a valores controvertidos para conjurar la inevitable consecuencia del desplazamiento del poder del parlamento al órgano de justicia constitucional.

16 Ignacio de Otto, Derecho Constitucional. Sistema de ${ }_{56} 6^{\text {Fuentes, Barcelona, Editorial Ariel, 1988, p. } 64 .}$ 
El especial papel de los jueces en el Estado constitucional como protectores o sujetos llamados a tutelar los derechos opacaría la necesidad de justificar el ejercicio de su actividad desde una óptica mayoritaria exclusivamente, dado que los derechos fundamentales serían ejercidos contra esa misma mayoría. ${ }^{17}$

En defensa de la justicia constitucional se argumentaría que, "en tanto el control judicial verse sobre las decisiones de la legislatura ordinaria y se ejercite para proteger los derechos básicos definidos por el poder constituyente originario, se trataría de un órgano verdaderamente democrático". ${ }^{18}$ Con lo cual, la tarea revisora consistiría únicamente en hacer cumplir las decisiones de la voluntad soberana objetivadas en la Constitución.

De ahí que "gracias al control judicial, la expresión más genuina de la voluntad popular (la Constitución) logra prevalecer frente a la expresión más atenuada de esa voluntad (la ley)". ${ }^{19}$ Un argumento que, aunque atractivo, afrontará algunas críticas justificadas.

En efecto, si se reconoce, como está claro, que "el catálogo de derechos que encontramos en la mayoría de constituciones recoge principios abstractos de moralidad

17 Luigi Ferrajoli "Justicia penal y democracia. El contexto extraprocesal” Jueces para la democracia, núm. 4., 1998, pp. 3 y ss.

18 Claudia Orunesu, Positivismo jurídico y sistemas constitucionales, Barcelona, Marcial Pons, 2012, p. 190 en una referencia a Hamilton, Madison y Jay.

19 Víctor Ferreres Comella, "El control Judicial de la constitucionalidad de la ley. El problema de su legitimidad democrática" en Miguel Carbonell y Leonardo García Jaramillo, El canon neoconstitucional, Colombia, Universidad Externado, 2010, p. 485. 
política, cuya interpretación es controvertida", ${ }^{20}$ se dificulta una defensa objetiva de una voluntad constituyente, y se coloca a los defensores de la revisión judicial de la constitucionalidad en la tesitura de ajustar sus argumentos, capaces de cerrar la denominada "brecha interpretativa". ${ }^{21}$

Y si esto se admite -que las Constituciones incorporan valores abstractos-, hay buenas razones para tomarse en serio la objeción contramayoritaria en contra de la revisión judicial, más aún, en sistemas en donde el grado de rigidez constitucional es mayor, ${ }^{22}$ "porque si el procedimiento de reforma constitucional es tan exigente que, en la práctica, su puesta en marcha es inviable, entonces los jueces constitucionales tienen de facto la última palabra sobre el contenido y alcance de los derechos básicos". ${ }^{23}$

20 Ibíd.

21 Roberto Gargarella ha definido que muchas de las críticas contramayoritarias se filtran a través de la denominada brecha interpretativa, es decir, en la amplitud y vaguedad a la que se puede prestar la interpretación constitucional. Véase, Roberto Gargarella, La justicia frente al gobierno. Sobre el carácter contramayoritario del poder judicial, Barcelona, Ariel, 1996, p. 59.

22 Alfonso Ruiz Miguel manifiesta que: “...con independencia de la supremacía constitucional, el control judicial en sí mismo no tiene por qué suscitar objeción contramayoritaria si no va acompañado de una cierta rigidez de la Constitución y, más aún, tal objeción, de estar justificada, tendrá más fuerza cuanto más alto sea el grado de rigidez" Véase, Alfonso Ruiz Miguel, "Constitucionalismo y democracia", en Isonomía, núm. 21, 2004, pp. 62-63.

23 Juan Carlos, Bayón, "Derechos, Democracia y Constitución", en Francisco Laporta, Constitución: problemas filosóficos, Madrid, Centro de Estudios Políticos y Constitucionales, 2003., p. 402. Por otro lado, una referencia normativa válida que encaja con este criterio es la disposición contenida en 58 


\section{Constitucionalismo y democracia}

La verdadera dimensión del problema se advierte al considerar que democracia y mayoritarismo, constitucionalismo y democracia, por una parte, se contraponen, ${ }^{24}$ pero, por otra, se complementan como dos caras de una misma moneda, dado que la democracia no puede concebirse en términos puramente formales para identificarse, sin más, como un simple procedimiento de

el art. 443 de la Constitución ecuatoriana, que confiere la facultad a la Corte Constitucional de determinar cuál de los procedimientos corresponde ser asumido para la reforma de la Constitución. Y es que, aun cuando el pueblo tenga la posibilidad de pronunciarse en una de las vías previstas, la Corte decidirá previamente cuál de ellas corresponde ser asumida, lo cual coloca el tema de la última palabra en manos de la propia Corte. En otro sentido opinarían Angélica Porras y Johanna Romero cuando consideran que los mecanismos agravados de reforma constitucional en el sistema ecuatoriano, no obstante constituir restricciones, no implican limitaciones a la democracia; de hecho manifiestan: "...las denominadas enmiendas y reformas constitucionales integran mecanismos de democracia directa para que sea el pueblo el que tenga la última palabra en materia de cambio constitucional". Véase, Angélica Porras Velasco y Johanna Romero Larco, Guía de Jurisprudencia constitucional ecuatoriana. Período octubre 2008-diciembre 2010, Quito, Corte Constitucional para el período de transición, 2011, Tomo I, p. 53.

24 Rodrigo Uprimny, “Estado de derecho", en Eunomía Revista en Cultura de legalidad, núm. 5, 2013, p.173, indica que, en su versión radical, las categorías democracia y Estado de Derecho entran en tensión y pueden ser consideradas opuestas, pues la democracia, en la medida en la que se funda en la soberanía popular, aspira al gobierno ilimitado del pueblo, mientras que el Estado de Derecho está asociado a la idea de gobierno dividido, limitado y reglado. 
toma de decisiones mayoritarias. ${ }^{25}$

25 Véase, Luigi Ferrajoli, "La democracia constitucional", en Christian Courtis (comp.), Desde otra mirada, Buenos Aires, Eudeba, 2009, pp. 431-448; Manuel Antonio Peña Freire, La garantía en el Estado Constitucional de derecho, Madrid, Trotta, 1997, pp. 64-75; Manuel Aragón, Constitución y control de poder, Buenos Aires, Edición Ciudad Argentina, 1995. p. 56. Este último autor indica que en realidad se trata de un falso enfrentamiento entre "democracia sustantiva y "democracia procedimental" - y dice-: "no es que sea falsa la distinción como distinción de facetas o cualidades, sino lo que resulta teóricamente falso es la contraposición como categorías opuestas"; Ignacio de Otto, "Derecho Constitucional. Sistema de Fuentes...", pp. 61, 64-65, manifiesta que "la justificación democrática de la restricción de la democracia no es difícil encontrar para aquellos preceptos constitucionales que contienen la fundamentación de la democracia misma y de los que los derechos fundamentales son el ejemplo más destacado...Si la democracia está esencialmente vinculada al pluralismo, está claro que se excluye la posibilidad de aplicar los métodos democráticos a su supresión, esto es, que tal supresión no podría llamarse decisión democrática. Afirmar lo contrario es tanto como admitir una omnipotencia que se destruye, algo que ni de Dios puede predicarse sin sofisma..."; Eduardo García de Enterría, Democracia, jueces y control de la Administración, Madrid, Civitas, 1997, pp. 65-66; Luigi Ferrajoli, Derechos y garantías: la ley del más débil, Madrid, Trotta, 2010, p. 25; Rodrigo Uprimny, Rodrigo Uprimny, "Estado de derecho", en Eunomía Revista en Cultura de legalidad, núm. 5, 2013, pp. 173 y ss., al tiempo que habla de una tensión, sin embargo, rescata la complementariedad de los términos; Robert Alexy, "Los derechos fundamentales en el Estado Constitucional democrático", en Miguel Carbonell, Neoconstitucionalismo(s), Madrid, Trotta, 2003, pp. 37-40 refiere que podrían existir tres formas de contemplar la relación entre derechos humanos y democracia: una ingenua, una idealista y una realista. Indica el autor que un Tribunal que intente responder 60 
No es posible, en efecto, predicar un concepto de democracia basado en el dominio absoluto e irrestricto de la mayoría. La democracia implica no solo un gobierno de la mayoría, sino también el respeto de unas minorías, y uno de los medios para asegurar ese cometido es la propia normatividad de la Constitución con unos límites a la actuación mayoritaria. ${ }^{26}$

La constante tensión entre constitucionalismo y democracia ha llevado a que se pueda hablar incluso de modelos intermedios de constitucionalismo, de un constitucionalismo débil como una variable del constitucionalismo democrático o de una respuesta democrático-constitucional, a medio camino entre la posición constitucionalista pura -del todo- y la posición radical democrática pura - del nada-. ${ }^{27}$

seriamente a las objeciones democráticas lo debe hacer desde una representación argumentativa, en la cual triunfa la reconciliación entre derechos y democracia.

26 Francisco Balaguer Callejon, "Constitución y ordenamiento jurídico" en Miguel Carbonell (comp.), Teoría de la Constitución, México, Editorial Porrúa, 2005, p. 199. Sin embargo, en este punto habrá que tener presente la advertencia de Roberto Gargarella sobre la revisión judicial, y es que, "...del hecho de que los jueces no representen a las mayorías, numéricamente hablando, no significa que los mismos representen (o, más bien, tengan una motivación especial para defender) a la infinita diversidad de minorías que existen en la sociedad...." Véase, Roberto Gargarella, "Del reino de los jueces al reino de los políticos" en Jueces para la democracia, núm. 28, 1997, p. 26.

27 Véase, Annette Schmitt, “¿Necesita la democracia una Constitución protegida?" en Pablo Navarro y Cristina Redondo (comp.), Larelevanciadelderecho, Barcelona, EditorialGedisa, 2002, pp. 254-262, quien ha utilizado tres tipos de respuesta frente a la tensión entre constitucionalismo y democracia: 
De hecho, la fórmula contemporánea de la democracia constitucional parece estar contenida en la aspiración a

La respuesta constitucionalista pura -del todo-; la respuesta del demócrata pura -del nada-; la respuesta del demócrata constitucional -del algo-. Sobre un constitucionalismo débil puede verse Juan Carlos Bayón, "Derechos, Democracia y Constitución", en Miguel Carbonell, Neoconstitucionalismo(s), Madrid, Trotta, 2003, pp. 234-235. El mismo Juan Carlos Bayón, con el título "Derechos, Democracia y Constitución" en Francisco Laporta, Constitución: problemas filosóficos, Madrid, Centro de Estudios Políticos y Constitucionales, 2003., pp. 418-419. Finalmente, Juan Carlos Bayón, "Democracia y Derechos: problemas de fundamentación del constitucionalismo...", pp. 351-355. Bayón propone un diseño que se caracterice por: i) defender la existencia de un coto vedado mínimo que ponga a resguardo de las mayorías unas reglas de procedimiento como, por ejemplo, el derecho a participar en términos igualitarios en la toma de decisiones, formulables en forma de reglas irreformables, reservando la textura abierta de los principios -como una ventaja instrumental- solo para aquellos contenidos que no es posible formular como reglas; ii) admitir la existencia de un sistema de justicia constitucional como mecanismo para incrementar la calidad de la práctica de deliberación previa a la toma de decisiones; iii) que se abandonen procedimientos de reforma que exigen gravosas mayorías calificadas como los que actualmente existen en los ordenamientos jurídicos; iv) otorgar la última palabra en cuestiones constitucionales a los mecanismos ordinarios de democracia representativa mediante técnicas como el reenvío. Habría que añadir que Pablo de Lora, sugiere en la línea del constitucionalismo débil, tener en cuenta la regla thayeriana, que no hace sino trasladar el estándar del procedimiento penal de la duda razonable al ámbito constitucional de la ley. Véase, Pablo de Lora "Justicia constitucional y deferencia al legislador", en F. Laporta, Constitución: problemas filosóficos, Madrid, Centro de Estudios Políticos y Constitucionales, 2003, pp. 361-366. 
un justo equilibrio entre el principio democrático dotado de valor constitucional y la idea de unos límites -derechos-, fijados mediante la fuerza normativa de la Constitución. ${ }^{28}$ Un equilibrio que, por ser de reciente adaptación, afecta a los sujetos protagonistas de esta conciliación, es decir, Parlamento y Tribunales. ${ }^{29}$

En ese contexto, y a pesar de que las Cortes o Tribunales Constitucionales no son el mejor ejemplo de lo que representa un órgano con legitimación democrática directa, dadas las credenciales democráticas que ostentan otros órganos dentro del Estado, básicamente, el legislador, sus decisiones pueden estimarse legítimas si aparecen como "aplicación"30 del Derecho en el marco de una teoría

28 Habermas apelaría en esta relación a la idea de la "cooriginalidad" o "copertenencia" de ambos ideales, ya que constituyen la manifestación de una misma concepción de las personas como sujetos morales que hace posible un ejercicio de autonomía política y autonomía privada. Véase, Jürgen Habermas, Facticidad y Validez. Sobre el derecho y el Estado democrático de derecho en términos de teoría del discurso, Madrid, Trotta, 2008, p. 193.

29 Maurizio Fioravanti, Constitución. De la antigüedad a nuestros días, Madrid, Trotta, 2001, p. 164.

30 Vale destacar que el término -aplicación-, en el presente trabajo, no será entendido como un acto puramente cognoscitivo-declarativo sobre el supuesto significado objetivo de las normas llevado a cabo por los órganos jurisdiccionales mediante un procedimiento de inferencia lógico-formal, tal como supusieron determinados planteamientos de la dogmática formalista decimonónica, ya que, de ser así, el debate acerca de la legitimidad de la justicia constitucional se vería anulado por el supuesto de un simple significado objetivo de la Constitución; por el contrario, el término aquí utilizado se halla orientado a un nivel de compresión de solución de problemas prácticos un tanto 
deliberativa de la democracia ${ }^{31}$ y de una teoría de la interpretación plausible que involucre prácticas dialógicas y no actitudes discrecionales o arbitrarias carentes de sustento. ${ }^{32}$

más difíciles, tratándose de normas constitucionales cuya estructura normativa es abierta, general e indeterminada, lo cual supone siempre una actividad concebida a medio camino entre la simple aplicación y la creación ex novo.

31 A pesar de que se puede hablar de un primer período de gestación de la democracia deliberativa y uno de consolidación posterior, una consulta sobre el origen y evolución del modelo deliberativo, así como un concepto de democracia deliberativa, puede consultarse en José Luis Martí, La república deliberativa, Marcial Pons, Madrid, 2006. Igualmente, puede verse Carlos Santiago Nino, La Constitución de la democracia deliberativa, Barcelona, Editorial Gedisa, 1997; Jürgen Habermas, Facticidad y Validez. Sobre el derecho y el Estado democrático de derecho en términos de teoría del discurso Madrid, Trotta, 1998, en lo referente al práctica deliberativa.

32 Tal como lo expresa María José Añón, "Como se trata por tanto de poner el acento en la esfera de la responsabilidad, la relación entre legitimación y discrecionalidad replantea una de las funciones del Derechos que es la de proveer unos parámetros de legitimación para orientar el comportamiento de funcionarios y ciudadanos. Desde esta perspectiva, suele argumentarse que el poder depositado en instituciones puede transformarse en autoridad en la medida en que los valores y prácticas que son aceptadas o constituyen expectativas en un determinado contexto social son sentidas como legitimas en dicho contexto. La aplicación de este presupuesto a la toma de decisiones por parte de los operadores jurídica lleva a considerar que esas decisiones deben reforzar o estimular el acuerdo u obtener la conformidad de los destinatarios de la decisión en sentido amplio". Véase, María José Añón, "Notas sobre discrecionalidad y legitimación", en Doxa. Cuadernos de Filosofía del Derecho. núm. 15-16, 1994, pp. 897-911. 
Las decisiones de las Cortes o Tribunales "pueden considerarse legitimas tan sólo si aparecen como aplicación del Derecho y no como creación política de normas. Este es el presupuesto que hace que para la jurisdicción constitucional llegue a ser de vital importancia asegurar su carácter jurisdiccional, porque dicho carácter constituye la fuente principal de legitimación de aquellos órganos del Estado llamados a aplicar las leyes y decidir sobre litigios concretos". ${ }^{33}$

Por ello, la tarea de proporcionar un marco de legitimidad ${ }^{34}$ apreciable a la revisión judicial descansa "en la

33 Claudia Storini, "Hermenéutica y Tribunal Constitucional", en Revista de Derecho FORO, Quito, núm. 7, 2007, p.160.

34 Pedro de Vega considera, apelando a una consideración weberiana, que "los términos legalidad y legitimidad terminan siendo expresiones coincidentes, en la medida en que el cumplimiento de la legalidad otorga por sí mismo legitimidad a la acción del gobernante" y por ello "la única forma de legitimidad posible de la que cabe hablar en la democracia posmoderna es de la legitimidad por el ejercicio". Véase, Pedro de Vega, "Legitimidad y representación en la crisis de la democracia actual" en Working papers-Documentos de trabajo, Barcelona, Instituto de Ciencias Políticas y Sociales, núm. 141, 1998", p 32. Por su parte, Alfonso Fernández Campoamor, en el prólogo a la obra de Esteban Delgado del Rincón, Constitución, poder judicial y responsabilidad, Centro de Estudios Políticos y Constitucionales, Madrid, 2002, p. 8, hace una distinción entre legitimidad y legitimación. Así, mientras la legitimidad es un concepto normativo, la legitimación es un concepto sociológico. Fernández Campoamor indica que así como al Parlamento le otorga legitimidad la voluntad de los electores, la legitimidad de las decisiones judiciales descansa en el propio Derecho que aplican los jueces y en la atribución de competencia que les confiere la Constitución, siempre que 
posibilidad de evaluar jurídicamente sus interpretaciones" 35 verificando de esta forma, que los jueces constitucionales, se han sometido al derecho que tiene que aplicar -la Constitución-.

Probablemente, y aun cuando una aproximación intuitiva en favor del control judicial de constitucionalidad esté asociada con situaciones en las cuales ciertas condiciones de la democracia no son satisfechas y, consecuentemente, lo político -llámese "democrático" o no- no es epistémicamente superior al proceso judicial. ${ }^{36}$

Si se han establecido ciertas restricciones al conjunto de decisiones que son tomadas por medio de la regla de la mayoría, mediante la incorporación de los denominados derechos fundamentales, es decir, ciertos derechos que no seencontrarían disponibles en la agendalegislativaordinaria por corresponder a los "momentos constitucionales", ${ }^{37}$ para diferenciarlos de los "momentos ordinarios"; hecho comúnmente conocido como el atrincheramiento de los derechos, y se ha confiado la guarda del texto constitucional a unos órganos especializados, ubicados en la cúspide reflexiva, ${ }^{38}$ al estilo de una Corte o Tribunal, la vigencia de

actúen sujetos al imperio de la ley. La legitimación -dicedescansa en el consenso social sobre la eficacia y la justicia.

35 Claudia Storini, "Hermenéutica y Tribunal Constitucional...", p.160.

36 Carlos Santiago Nino, "La Constitución de la democracia deliberativa...", p. 272.

37 Bruce Ackerman y Carlos Rosenkrantz, "Tres concepciones de la democracia constitucional" en Cuadernos y Debates, Fundamentos y alcances del control judicial de constitucionalidad, núm. 29, Madrid, Centro de Estudios Políticos y Constitucionales, 1991.

38 Jürgen Habermas, “Facticidad y Validez...", p. 313. 66 
la justicia constitucional dentro de un Estado democrático, dada su expansión y consolidación, desplaza el centro de atención del debate del quién ${ }^{39}$ al qué se decide, y al cómo desplegar esta tarea de manera que se pueda abrazar un grado de legitimidad aceptable que procure una conciliación entre el constitucionalismo y la democracia. ${ }^{40}$

Es claro, entonces, que la objeción contramayoritaria se advierte de forma conjunta en dos frentes: en el marco del control abstracto de constitucionalidad en relación con normas inferiores a la Constitución y, en la idea de unos derechos constitucionales atrincherados, expresados mediante fórmulas abstractas o generales asociados con la idea de rigidez constitucional. ${ }^{41}$

39 De hecho, un dato que la Corte Constitucional ecuatoriana ha pretendido dejar claro es que, es ésta, la Corte Constitucional ecuatoriana, el órgano que ostenta la última palabra dentro del sistema constitucional. En la sentencia 019-12-SINCC, dijo lo siguiente: “...los jueces constitucionales en el Ecuador tienen la última palabra sobre los derechos en prácticamente cualquier cuestión que se plantee en la sociedad, desplazando adecuadamente, a los órganos que participan en el proceso democrático...".

40 Sobre una crítica a los momentos constituyentes para diferenciarlos de los momentos de política ordinaria puede verse un pasaje de Francisco Laporta en "Materiales para una reflexión sobre la racionalidad y la crisis de la ley", en Doxa. Cuadernos de Filosofía del Derecho, núm. 22, 1999, pp. 328-329.

41 A decir de Ferreres Comella son tres las circunstancias que dan lugar a la denominada dificultad contramayoritaria: 1) La legitimidad democrática de origen del juez, dado que la ley que hay que enjuiciar proviene de un parlamente electo democráticamente; 2) La rigidez constitucional, dado que la Constitución en este supuesto solo puede reformarse mediante un procedimiento agravado; y, 3) La 
Ahora bien, si se acepta la premisa de la consolidación y expansión de la revisión judicial ¿cuál es el coste que está dispuesta a asumir una sociedad que se estima democrática con el fin de soportar dicha revisión con todas las dudas que la aquejan? ¿Es posible admitir una revisión judicial compatible con el ideal democrático? ¿Cuáles son los argumentos que justifican una revisión judicial?

A pesar de la vitalidad del debate, que ha sido bastante prolijo así como abundante en la teoría jurídica norteamericana, parecería contraintuitivo en el contexto de esta investigación pensar que para el caso ecuatoriano, la justicia constitucional pueda aparecer como un órgano antidemocrático capaz de torcer la voluntad popular a pretexto de interpretar la Constitución, debido al carácter garantista ${ }^{42}$ que subyace a la carta constitucional vigente

controvertibilidad interpretativa de la Constitución, dado que las Constituciones se conforman en abundancia de conceptos jurídicos indeterminados. Véase, Víctor Ferreres Comella, "Justicia Constitucional y democracia...", p. 43.

42 Sobre el garantismo puede consultarse la obra de Luigi Ferrajoli, Democracia y garantismo Madrid, Trotta, 2008, pp. 61-62, donde se indica que la expresión garantismo constituye un neologismo para referirse a las técnicas de tutela de los derechos fundamentales, así como para designar al conjunto de límites y vínculos impuestos a todos los poderes, públicos y privados, políticos (o de mayoría) y económicos (o de mercado), en el plano estatal e internacional, que surgió en la cultura jurídica italiana de izquierda en la segunda mitad de los años setenta, como respuesta teórica a la legislación y a la jurisdicción que redujeron de diferentes formas el sistema de garantías procesales. Véase, también, Luigi Ferrajoli, Garantismo. Una discusión sobre derecho y democracia, Madrid, Trotta, 2006. Una visión crítica de la utilización del término "garantismo" puede consultarse en Manuel Aragón Reyes, "Dos problemas falsos y uno verdadero: 
y al hecho de que la Corte Constitucional del Ecuador ha asumido el papel de guardián "natural" de la norma fundamental.

Aún más, puede sostenerse que el debate es intrascendente en el modelo ecuatoriano, por cuanto la institución de la revisión judicial tiene una fuente democrática en su origen, como es su inclusión en una norma fundamental aprobada democráticamente. Sin embargo, de ello no se colige que pueda seguirse calificando indubitadamente como tal, si, en la práctica, la revisión judicial no se ajusta a unas exigencias verdaderamente democráticas compatibles con el ideal del constitucionalismo. ${ }^{43}$

De hecho, el péndulo parece haber oscilado en términos extremos, desde una confianza acrítica en la Corte Constitucional y, en consecuencia, su aceptación o

"neoconstitucionalismo", "garantismo" y aplicación judicial de la Constitución...”, pp. 3 y ss.

43 Como explica Víctor Ferreres Comella, la problemática parecería relevante desde el punto de vista de los Estados Unidos y no en España porque, en el último caso, dice el autor, la justicia constitucional está expresamente establecida en el texto constitucional aprobado democráticamente, mientras en los Estados Unidos no es así. Sin embargo, una cosa es que una institución sea o no compatible con la democracia -que es lo que hace falta discutir- y otra que su existencia sea el producto de una decisión democrática. Para ello pone el ejemplo de la Monarquía prevista en una Constitución que puede ser democrática en el momento de su aprobación, pero no se ajusta a las exigencias estructurales de una democracia. En igual sentido, la institución de la revisión judicial puede parecer como una institución cuya estructura objetiva es contradictoria con la democracia. Véase, Víctor Ferreres Comella, "Justicia constitucional y democracia...", p. 47. 
aprobación natural; a una exagerada desconfianza y su consecuente rechazo, obviando la relevancia del debate que oriente a la toma de una posición sólida.

Poner en cuestión una "obviedad", "la naturalidad" del guardián de la Constitución que reside en las Cortes o Tribunales, puede representar una empresa complicada; no obstante, lo que debe interesar es evidenciar la importancia y la actualidad del debate contramayoritario y los giros que puede estar tomando el mismo más allá de asunciones apriorísticas.

\section{Ideas finales a modo de conclusión}

Intentar construir una respuesta satisfactoria, si es que la hay, a la objeción democrática, admitiendo que no se trata de un tema pacífico, es el reto que se presenta más allá de simples estipulaciones terminológicas o asunciones apriorísticas.

Frente a lo que podría estimarse un denominado "punto de no retorno" en relación con la expansión y consolidación del modelo de revisión judicial, la idea debe pasar por aportar argumentos válidos que sustenten lo que puede considerarse un ejercicio legítimo y tolerable de la vigencia del órgano de control en una democracia tanto desde el punto de vista interno, ${ }^{44}$ así como, desde un punto de

$44 \quad$ Dicho objetivo se puede alcanzar recurriendo a mecanismos de legitimidad democrática que miren a la práctica interna del órgano de revisión con respecto a la forma de adoptar sus decisiones en el marco de una visión deliberativa de la democracia y un constitucionalismo dialógico, así como a la utilización de criterios interpretativos, de argumentación y 70 motivación válidos como parámetros objetivables. 
vista externo ${ }^{45}$ capaz de articular una relación necesaria entre soberanía popular, participación ciudadana y justicia constitucional.

\section{Bibliografía}

Ackerman, Bruce y Rosenkrantz, Carlos, "Tres concepciones de la democracia constitucional" en Cuadernos y Debates, Fundamentos y alcances del control judicial de constitucionalidad, núm. 29, Madrid, Centro de Estudios Políticos y Constitucionales, 1991.

Ackerman, Bruce, We the People. Foundations, Cambridge, Massachussets: Harvard University Press, 1991.

Alexy, Robert, "Los derechos fundamentales en el Estado Constitucional democrático", en Miguel Carbonell, Neoconstitucionalismo(s), Madrid, Trotta, 2003.

Añón, María José, “Notas sobre discrecionalidad y legitimación", en Doxa. Cuadernos de Filosofía del Derecho. núm. 15-16, 1994.

Aragón, Manuel, Constitución y control de poder, Buenos Aires, Edición Ciudad Argentina, 1995.

Balaguer Callejon, Francisco, "Constitución y ordenamiento jurídico" en Miguel Carbonell (comp.), Teoría de la Constitución, México, Editorial Porrúa, 2005.

Bayón, Juan Carlos, "Democracia y derechos: problemas de fundamentación del constitucionalismo", en Miguel Carbonell y Leonardo García Jaramillo, Neoconstitucionalismos, Madrid, Trotta, 2010.

45 La forma de integración y composición del órgano de revisión judicial y sobre cuáles pueden constituir opciones válidas en una democracia. 
Bayón, Juan Carlos, "Derechos, democracia y Constitución" en F. Laporta (ed.), Constitución: Problemas filosóficos, Madrid, CEPC, 2003.

, "Derechos, Democracia y Constitución" en Francisco Laporta, Constitución: problemas filosóficos, Madrid, Centro de Estudios Políticos y Constitucionales, 2003.

, "Derechos, Democracia y Constitución", en Miguel Carbonell, Neoconstitucionalismo(s), Madrid, Trotta, 2003.

Bickel, Alexander, The Least Dangerous Branch: The Supreme Court at the Bar of Politics, 2da. ed., Yale University Press, 1986.

Bon, Pierre, "Francia" en Eliseo Aja (edit.), "Las tensiones entre el Tribunal Constitucional y el legislador en la Europa actual", Barcelona, Ariel, 1998.

Cascajo Castro, José Luis "La jurisdicción constitucional de la libertad" en Revista de Estudios Políticos, núm. 199, 1999.

De Lora, Pablo, "Justicia constitucional y deferencia al legislador" en F. Laporta (ed.), Constitución: Problemas filosóficos, Madrid, CEPC, 2003.

De Otto, Ignacio, Derecho Constitucional. Sistema de Fuentes, Barcelona, Editorial Ariel, 1988.

De Vega, Pedro, "Legitimidad y representación en la crisis de la democracia actual" en Working papers-Documentos de trabajo, Barcelona, Instituto de Ciencias Políticas y Sociales, núm. 141, 1998. 
Dworkin, Ronald, Freedom's Law. The moral Reading of the American Constitution, Cambridge: Harvard University Press, 1996.

Ely, John, Democracia y Desconfianza Una teoría del control constitucional (Democracy and Distrust), Colombia, Universidad de los Andes, Siglo del Hombre Editores, 1997.

Ferrajoli, Luigi "Justicia penal y democracia. El contexto extraprocesal” Jueces para la democracia, núm. 4., 1998.

, "La democracia constitucional", en Christian Courtis (comp.), Desde otra mirada, Buenos Aires, Eudeba, 2009.

, Democracia y garantismo Madrid, Trotta, 2008.

- Derechos y garantías: la ley del más débil, Madrid, Trotta, 2010.

, Garantismo. Una discusión sobre derecho y democracia, Madrid, Trotta, 2006.

FerreresComella,Víctor,"ElcontrolJudicialdelaconstitucionalidad de la ley. El problema de su legitimidad democrática" en Miguel Carbonell y Leonardo García Jaramillo, El canon neoconstitucional, Colombia, Universidad Externado, 2010.

, Justicia Constitucional y democracia, Madrid, CEPC, 1997.

, "Una defensa de la rigidez constitucional" en F. Laporta (ed.), Constitución: Problemas filosóficos, Madrid, CEPC, 2003. 
Ferreres Comella, Víctor, "El controljudicial de laconstitucionalidad de la ley. El problema de su legitimidad democrática" en Miguel Carbonell y Leonardo García Jaramillo, Neoconstitucionalismos, Madrid, Trotta, 2010.

Fioravanti, Maurizio, Constitución. De la antigüedad a nuestros días, Madrid, Trotta, 2001.

García de Enterría, Eduardo, Democracia, jueces y control de la Administración, Madrid, Civitas, 1997.

, La Constitución como norma y el Tribunal Constitucional, 4ta. ed., Madrid, Civitas, 2006.

, "Constitucionalismo versus Democracia" en Teoría y crítica del derecho constitucional, Abeledo Perrot, 2008.

, "Del reino de los jueces al reino de los políticos" en Jueces para la democracia, núm. 28, 1997.

"Las amenazas del constitucionalismo: constitucionalismo, derechos y democracia", Los derechos fundamentales, Marcelo Alegre, ed. al., Buenos Aires, Editores del Puerto, 2003.

- La justicia frente al gobierno. Sobre el carácter contramayoritario del poder judicial, Barcelona, Ariel, 1996.

Habermas, Jurgen Facticidad y Validez. Sobre el derecho y el Estado democrático de derecho en términos de teoría del discurso, Madrid, Trotta, 2008.

Kelsen, Hans, ¿Quién debe ser el defensor de la Constitución?, Madrid, Tecnos, 1995. 
Kelsen, Hans, Esencia y valor de la democracia, 2da. ed., Madrid, Guadarrama, 1977. trad. Rafael Luengo Tapia y Luis Legaz y Lacambra.

Kramer, Larry, The People Themselves. PopularConstitucionalism and Judical Review, Oxford University Press, New York, 2004.

Lambert, Edouard, El gobierno de los jueces y la lucha contra la legislación social en los Estados Unidos, con estudio preliminar de Luis Pomed, Madrid, Tecnos, 2010, trad. Félix de la Fuente.

Laporta, Francisco, "Norma básica, constitución y decisión por mayorías" en F. Laporta (ed.), Constitución: Problemas filosóficos, Madrid, CEPC, 2003.

, "Materiales para una reflexión sobre la racionalidad y la crisis de la ley", en Doxa. Cuadernos de Filosofía del Derecho, núm. 22, 1999.

Martí, José Luis, La república deliberativa, Marcial Pons, Madrid, 2006.

Moreso, José Juan, "Derechos y justicia procesal imperfecta" en Francisco Laporta, Constitución: problemas filosóficos, Madrid, Centro de Estudios Políticos y Constitucionales, 2003.

Nino, Carlos Santiago, La Constitución de la democracia deliberativa, Barcelona, Editorial Gedisa, 1997.

, Fundamentos de derecho constitucional, Buenos Aires, Editorial Astrea, 1992.

- La Constitución de la democracia deliberativa, Barcelona, Gedisa, 1997. 
Noguera, Albert, ¿Democratizando la justicia constitucional? La articulación entre soberanía, justicia constitucional y participación en el viejo y el nuevo constitucionalismo, en Oñati Socio-Legal Series, v. 1, n. 2.

Orunesu, Claudia, et. al "Los límites de la interpretación en la democracia constitucional" en Estudios sobre la interpretación dinámica de los sistemas constitucionales, México, Biblioteca de Ética, Filosofía del Derecho y Sociedad, Fontamará S.A, 2005.

Orunesu, Claudia, Positivismo jurídico y sistemas constitucionales, Madrid, Marcial Pons, 2012; Sebastián Linares, La (i)legitimidad del control judicial de las leyes, Madrid, Marcial Pons, 2008.

, Positivismo jurídico y sistemas constitucionales, Barcelona, Marcial Pons, 2012.

Pardo Falcón, Javier, El Consejo Constitucional Francés. Madrid, Centro de Estudios Constitucionales, 1990.

Peña Freire, Manuel Antonio, La garantía en el Estado Constitucional de derecho, Madrid, Trotta, 1997.

Pintore, Anna, "Democracia sin derechos. En torno al Kelsen democrático", en Doxa. Cuadernos de Filosofía del Derecho, núm. 23, 2000.

Porras Velasco, Angélica y Romero Larco, Johanna, Guía de Jurisprudencia constitucional ecuatoriana. Período octubre 2008-diciembre 2010, Quito, Corte Constitucional para el período de transición, 2011, Tomo I.

Rodríguez-Aguilera de Prat, Cesáreo, "Norberto Bobbio y el Futuro de la Democracia" en Working papersDocumentos de trabajo, Barcelona, Instituto de Ciencias Políticas y Sociales, núm. 125, 1997. 
Ruiz Miguel, Alfonso, "Constitucionalismo y democracia", en Isonomía, núm. 21, 2004.

Schmitt, Annette, "¿Necesita la democracia una Constitución protegida?" en Pablo Navarro y Cristina Redondo (comp.), La relevancia del derecho, Barcelona, Editorial Gedisa, 2002.

Schmitt, Carl, La Defensa de la Constitución, Madrid, Tecnos, 1983.

Storini, Claudia, "Hermenéutica y Tribunal Constitucional", en Revista de Derecho FORO, Quito, núm. 7, 2007.

Tushnet, Mark, ¿Por qué la Constitución importa? Serie de Teoría Jurídica y Filosofía del derecho. Nro. 63, Colombia, Universidad Externado, 2012.

Uprimny, Rodrigo, "Estado de derecho", en Eunomía Revista en Cultura de legalidad, núm. 5, 2013.

Waldron, Jeremy, Derecho y Desacuerdos, (Law and Disagreement) Madrid, Marcial Pons, Ediciones Jurídicas y Sociales S.A., 2005.

Zagrebelsky, Gustavo, Principios y votos. El Tribunal Constitucional y la política, Madrid, Trotta, 2008. 